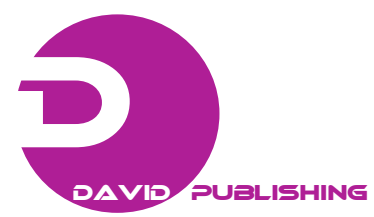

\title{
Effect of Low-pressure Carbonation on the Heat Inactivation and Cytoplasmic Acidification of Saccharomyces cerevisiae
}

\author{
Wannaporn Klangpetch ${ }^{1}$, Tomoe Nakai ${ }^{1}$, Kei Nishiyama ${ }^{1}$, Seiji Noma ${ }^{2}$, Noriyuki Igura ${ }^{2}$ and Mitsuya Shimoda ${ }^{2}$ \\ 1. Graduate School of Bioresource and Bioenvironmental Sciences, Kyushu University, Fukuoka, Japan \\ 2. Division of Bioresources and Bioenvironmental Sciences, Kyushu University, Fukuoka, Japan
}

Received: October 8, 2012 / Published: December 20, 2012.

\begin{abstract}
Effect of low-pressure carbonation (LPC) on heat inactivation of Saccharomyces cerevisiae was investigated. The cell suspension was carbonated at $1 \mathrm{MPa}$ and $4{ }^{\circ} \mathrm{C}$ for $15 \mathrm{~min}$ and subsequently heated from 51 to $61^{\circ} \mathrm{C}$ and $5 \mathrm{~s}$ to 5 min (heating with LPC). As a control experiment, cell suspension was heat-treated under atmospheric pressure without LPC (heating). The inactivation ratio of heating at $53{ }^{\circ} \mathrm{C}$ and $55{ }^{\circ} \mathrm{C}$ for 1 min with LPC was approximately 1 log order higher than heating alone. Extending heating time to 5 min did not widen the difference in the inactivation ratio between heating with LPC and heating alone at both heating temperatures. At $57^{\circ} \mathrm{C}$, the difference in inactivation ratio increased from 1 to $2.5 \log$ order with extending treatment time from 5 to $15 \mathrm{~s}$. The results suggested that the enhanced inactivation effect by LPC was obtained at the higher temperature with short time treatment than the lower temperature with longer time treatment. Under fluorescence microscope observation of LPC-treated cell stained with LysoSensor probe, it seemed that LPC was hardly able to acidify the cytoplasm of S. cerevisiae. It is considered that the ability of S. cerevisiae cells to keep their cytoplasmic pH during LPC resulted in the inferior increase in heat inactivation ratio by LPC as compared with bacteria in the previous studies.
\end{abstract}

Key words: Saccharomyces cerevisiae, low-pressure carbonation, heat inactivation, heat sensitivity.

\section{Introduction}

The incidents of microbial deterioration of liquid foods such as several kinds of fruit juice are the most frequently due to the fermentative yeast, Saccharomyces cerevisiae [1, 2] which causes ethanolic spoilage, production of hydrogen sulfide and other off-odors [3]. Therefore, it is necessary to eliminate $S$. cerevisiae to provide an appropriate shelf-life of the liquid foods.

Heat treatment is the most frequently accomplished in commercial pasteurization of liquid foods. Although it can provide high inactivation effect, the heat treatment with severe conditions typically produces

Corresponding author: Seiji Noma, assistant professor, research field: food process engineering. E-mail: nomas@agr.kyushu-u.ac.jp. cooked flavors which can affect the original aromas and flavors of the fresh liquid foods. Furthermore, it can cause the loss of nutrients and vitamins. To meet the consumer's requirement for fresh-like liquid foods, there is a growing interest in non-thermal processes for the preservation. In addition, preservatives such as benzoic acid can exhibit optimum activity in the $\mathrm{pH}$ range of 2.5-4.0 [4]. Sulfur dioxide and sorbic acid are also commonly used to inhibit mold and yeast in fruit juices [5]. Besides, the application of irradiation technology is available and now legally permitted in more than 40 countries such as USA, Germany, France and Brazil [6]. Unfortunately, consumer attitudes toward the use of the preservatives and irradiation have so far limited. Removal of microorganisms by physical methods such as centrifugation and ultrafiltration are also reported. Other physical methods, such as 
utilization of pulsed electric fields and high hydrostatic pressure, are also widely studied [7]. High hydrostatic pressure has been investigated as a method to stabilize liquid foods at reduced temperatures by inactivating the microbial cells [8]. The high-pressure treatment of $400 \mathrm{MPa}$ at $20^{\circ} \mathrm{C}$ for $30 \mathrm{~min}$ was revealed to cause a $3.51 \log$ reduction of $S$. cerevisiae [9]. Nevertheless, the large financial investment required for the high pressures equipment [10].

$\mathrm{CO}_{2}$ is accepted as an innocuous ingredient in foods because it is nontoxic, inflammable, inexpensive and environmentally safe. Water-dissolved $\mathrm{CO}_{2}$ also inactivates various microbial cells [11, 12]. A 7 log order of $S$. cerevisiae cells can be inactivated at 1,000 psi (6.9 MPa), for $15 \mathrm{~min}$ at room temperature [10]. Although there are many studies which investigated the effect of high-pressure and supercritical $\mathrm{CO}_{2}$ in microbial inactivation, the effect of the low-pressure is quite rarely studied. In previous study, we investigated that low-pressure carbonation (LPC) can not significantly inactivate microbial cells itself, but can increase the heat sensitivity of the microbial cells. We carbonated several microbial cell suspensions and subsequently heated for $1 \mathrm{~min}$ at temperatures ranging from $50{ }^{\circ} \mathrm{C}$ to $70{ }^{\circ} \mathrm{C}$ at $1 \mathrm{MPa}$ compared with heating under atmospheric pressure, heating with LPC exhibited 3-5 log inactivation on several bacteria [13]. In present study, we decided to explore the most appropriate condition of heating temperature and time under the LPC in an effort to facilitate the LPC's enhancing effect on heat inactivation of $S$. cerevisiae.

\section{Materials and Methods}

\subsection{Preparation of Cell Suspension}

S. cerevisiae NBRC 10217 was obtained from the National Institute of Technology and Evaluation (Tokyo, Japan). The cells were precultured in $5 \mathrm{~mL}$ of yeast malt peptone (YM) broth (Difco, Detroit, USA) at $30{ }^{\circ} \mathrm{C}$ for $24 \mathrm{~h}$, and $3 \mathrm{~mL}$ of the resulting culture was inoculated into $200 \mathrm{~mL}$ of freshly prepared YM broth. This culture was incubated to attain the late logarithmic growth phase. Cells were harvested and washed three times by centrifugation at 2,000 $\times$ g at $4{ }^{\circ} \mathrm{C}$ for $10 \mathrm{~min}$ in $0.85 \% \mathrm{w} / \mathrm{v}$ sodium chloride solution, and the pellet was resuspended in the solution to yield a final cell concentration of $10^{8}$ colony forming units (CFU)/mL. This cell suspension was subjected to the inactivation treatments described below.

\subsection{Inactivation Treatments}

Three treatments (LPC, heating with LPC and heating) were performed. Schematic diagram of the apparatus used for the LPC and heating is shown in Fig. 1.

\subsubsection{LPC}

The $S$. cerevisiae cell suspension was poured into a $\mathrm{CO}_{2}$-dissolving vessel. $\mathrm{CO}_{2}$ gas was then introduced into the vessel at a pressure of $1 \mathrm{MPa}$, and dissolved into the cell suspension by stirring at $4{ }^{\circ} \mathrm{C}$ for $15 \mathrm{~min}$ to the point of saturation. The saturation of $\mathrm{CO}_{2}$ in the cell suspension was confirmed by the method of Shimoda [14].

\subsubsection{Heating with LPC}

The LPC-treated suspension was introduced into the residence column adjusted to $51-61{ }^{\circ} \mathrm{C}$ in a water bath. After heating for $5 \mathrm{~s}-5 \mathrm{~min}$ in the residence column at 1 MPa, the cell suspension was withdrawn through a flow rate control valve. During heating, the $\mathrm{CO}_{2}$ concentration in the cell suspension was kept saturated at $1 \mathrm{MPa}$ at each temperature.

\subsubsection{Heating}

The $S$. cerevisiae cell suspension in the $\mathrm{CO}_{2}$-dissolving vessel was introduced into a residence column in the water bath using the pressure of oxygen gas. After heating at $51-61{ }^{\circ} \mathrm{C}$ for $5 \mathrm{~s}-5 \mathrm{~min}$ in the column under atmospheric pressure (0.1 MPa), the cell suspension was withdrawn through a flow rate control valve.

\subsection{Determination of Inactivation Ratio}

Appropriate serial dilutions of each sample were prepared in a $0.85 \%$ sodium chloride solution; $0.1 \mathrm{~mL}$ of the suspension was plated onto YM agar (Difco, 


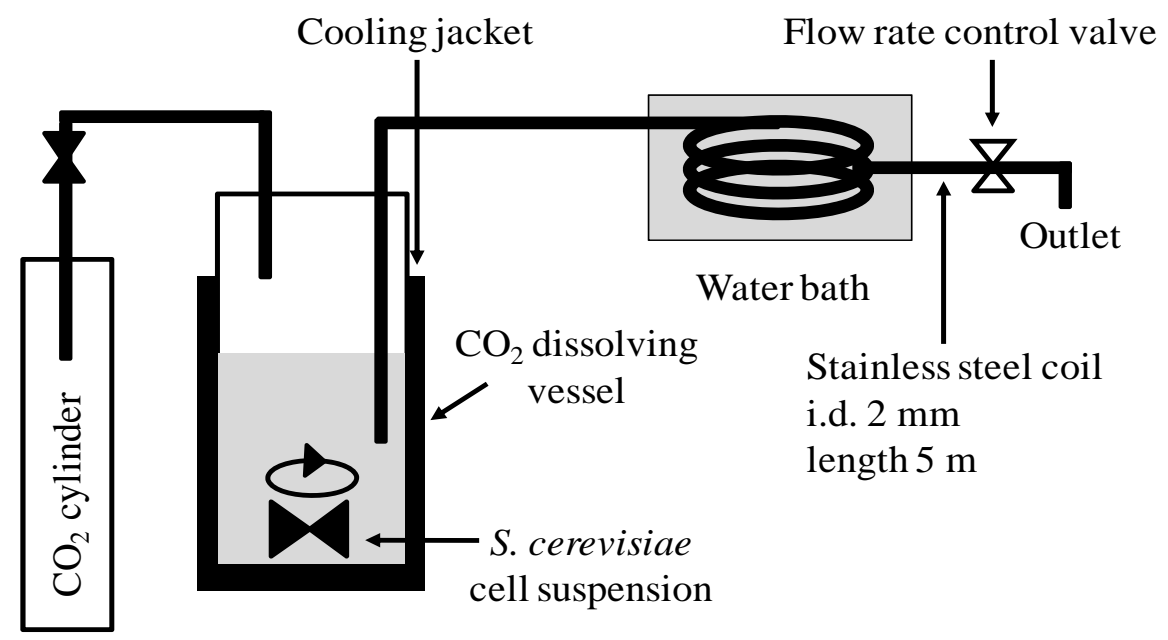

Fig. 1 Schematic diagram of the apparatus used for LPC and heating.

Detroit, USA) plate; and the number of forming colony was enumerated after incubation at $30^{\circ} \mathrm{C}$ for $48 \mathrm{~h}$. The inactivation ratio was expressed as $\log \left(N_{0} / N\right)$, where $N_{0}$ is the initial colony count and $N$ is the colony count after each treatment. The inactivation ratio was determined as the mean \pm standard deviation of three independent experiments.

\subsection{LysoSensor Probe Staining}

To evaluate the effect of LPC on cytoplasmic acidification of $S$. cerevisiae cells, the LPC-treated (1 $\left.\mathrm{MPa}, 4{ }^{\circ} \mathrm{C}, 15 \mathrm{~min}\right) \mathrm{S}$. cerevisiae cells were stained with LysoSensor Yellow/Blue DND-160 (Molecular probes, Invitrogen Inc., OR, USA), according to the manufacture's protocol, the fluorescent $\mathrm{pH}$ indicator partitioning into acidic organelles. The LysoSensor-stained cells were observed under a microscope (BX 50, Olympus Co.) equipped with accessories for fluorescence observation (BH2-RFL-T3, U-ULS100HG, and BX-KLA; Olympus Co.). In addition, the high pressure carbonation (HPC)-treated cell (5 MPa, $30^{\circ} \mathrm{C}, 15 \mathrm{~min}$ ) was also observed as a positive control for the acidified cell.

\section{Results and Discussion}

\subsection{Effect of Heating with LPC on the Inactivation of S.} cerevisiae Cells

Inactivation effects of $51{ }^{\circ} \mathrm{C}$ to $61{ }^{\circ} \mathrm{C}$ heating temperature to $S$. cerevisiae were compared between heating and heating with LPC for 1 min heating time (Fig. 2). At $51{ }^{\circ} \mathrm{C}$, the inactivation ratio of heating was almost not able to be detected and the same result was also observed when heating with LPC. Heating at $53{ }^{\circ} \mathrm{C}$ and $55^{\circ} \mathrm{C}$ with LPC showed higher inactivation ratio than heating alone for 1.15 and $1.25 \log$ order, respectively. In addition to the previous study, herein it can be firstly suggested that not only the bacteria [13], but also $S$. cerevisiae LPC can increase the heat sensitivity. However, the LPC-increased heat sensitivity of $S$. cerevisiae seemed to be different depending on the level of heating temperatures. At the heating temperature of $57{ }^{\circ} \mathrm{C}$, the enhanced heat inactivation level by LPC was smaller than the inactivation level at 53 and $55{ }^{\circ} \mathrm{C}$, and gradually decreased with the increasing temperature. It was proposed that at a particular heating temperature and time, the acquisition of heat resistance of $S$. cerevisiae can be triggered [15]. From this, it can be suggested that the heat sensitivity of $S$. cerevisiae decreased during the heating temperatures rising from 59 to $61{ }^{\circ} \mathrm{C}$ at 1 min heating time. Besides, the LPC-increased heat sensitivity also decreased during the temperatures rising from 57 to $61{ }^{\circ} \mathrm{C}$.

Fig. 3 shows the effect of the heating time from 1 to $5 \mathrm{~min}$ on the inactivation ratio of $\mathrm{S}$. cerevisiae at $53^{\circ} \mathrm{C}$ (Fig. 3a) and $55^{\circ} \mathrm{C}$ (Fig. 3b) when heating with LPC 


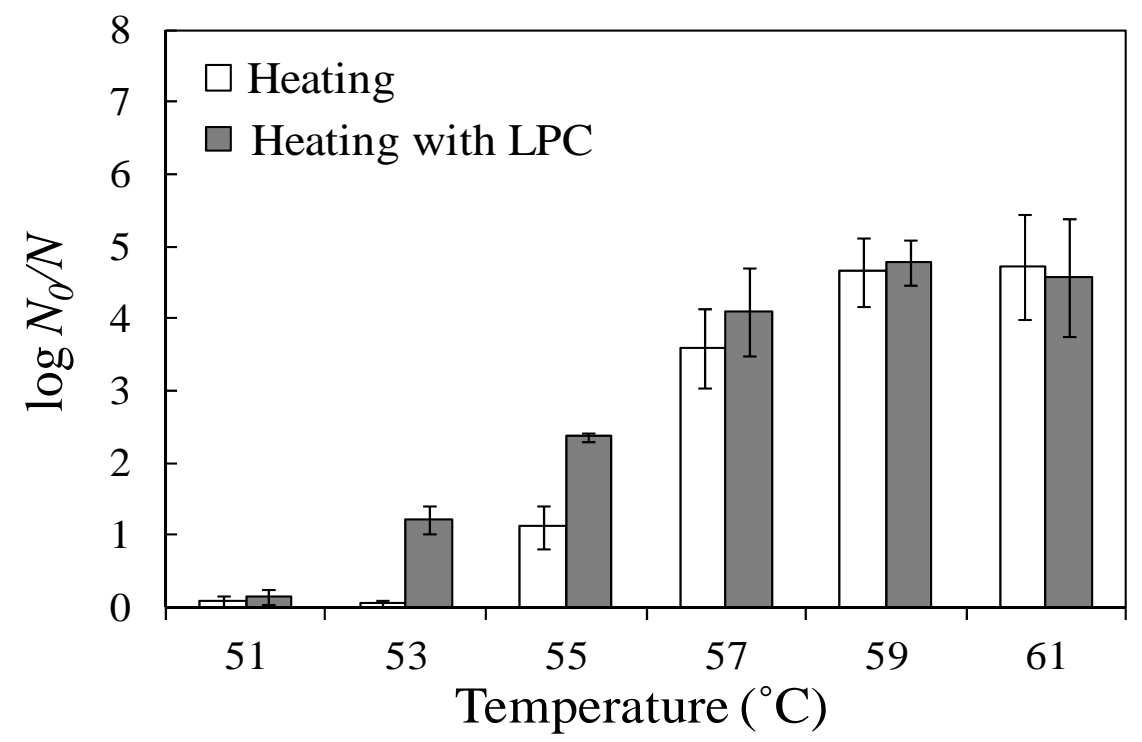

Fig. 2 Effect of heating (0.1 MPa, 51-61 $\left.{ }^{\circ} \mathrm{C}, 1 \mathrm{~min}\right)$ and heating with LPC (1 MPa, 51-61 $\left.{ }^{\circ} \mathrm{C}, 1 \mathrm{~min}\right)$ on log inactivation ratio of $S$. cerevisiae. The initial cell concentration was $10^{8} \mathrm{CFU} / \mathrm{mL}$.
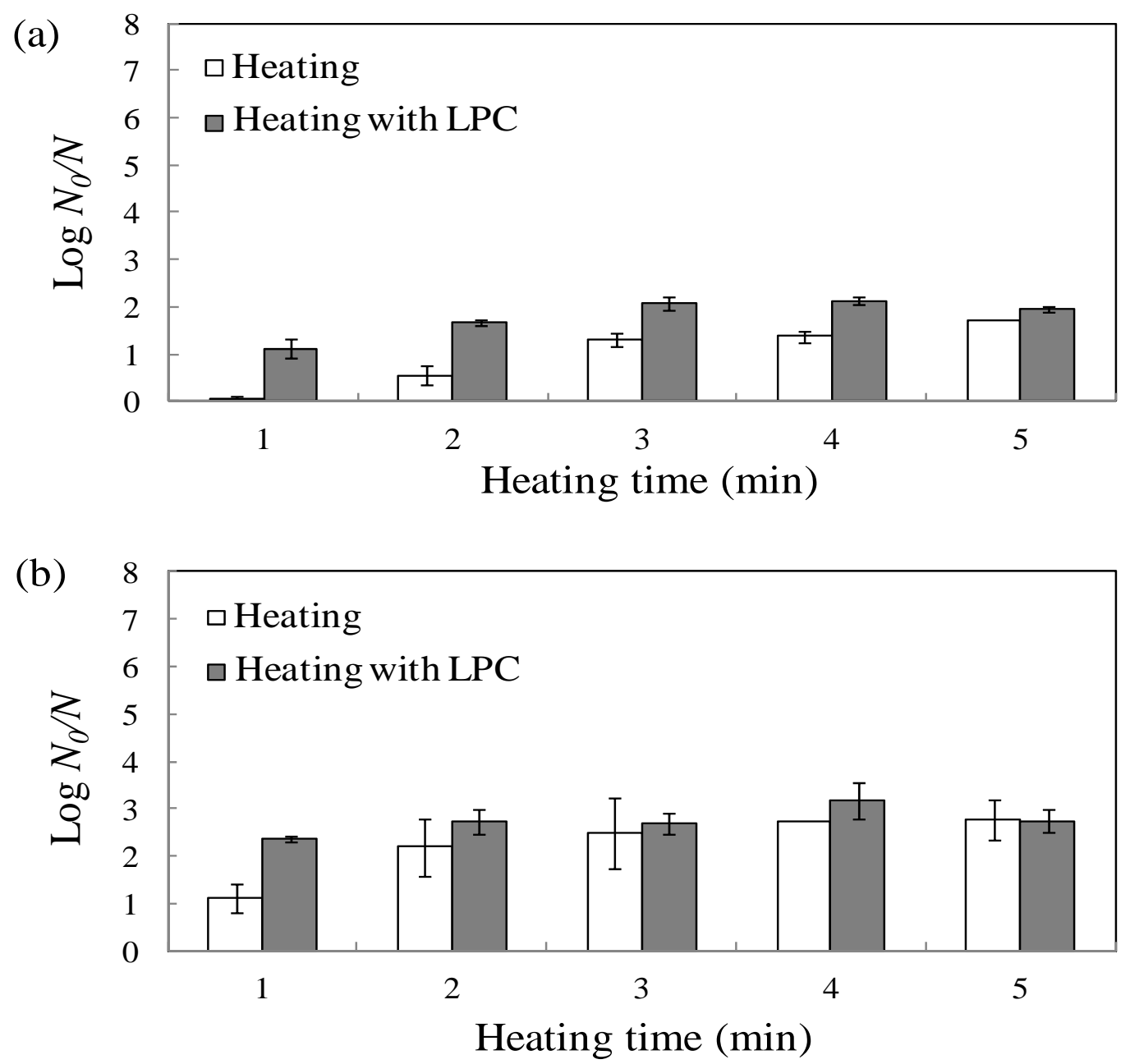

Fig. 3 Effect of heating treatment time on $\log$ inactivation ratio of $S$. cerevisiae after heating $(0.1 \mathrm{MPa}, 1 \mathrm{~min})$ and heating with LPC (1 MPa, $1 \mathrm{~min}$ ). (a) $53^{\circ} \mathrm{C}$; (b) $55^{\circ} \mathrm{C}$. The initial cell concentration was $10^{8} \mathrm{CFU} / \mathrm{mL}$. 
and heating alone. At $53{ }^{\circ} \mathrm{C}$ for 1 and 2 min treatment, LPC could enhance the heat inactivation for 1.15 and $1.14 \log$ order, respectively. Then, the enhanced inactivation ratio gradually decreased with the extending heating time to nearly undetectable at $5 \mathrm{~min}$ heating time. At $55{ }^{\circ} \mathrm{C}$ for 1 min treatment, LPC could enhance the heat inactivation for $1.25 \log$ order. Then, the enhanced inactivation ratio decreased to $0.54 \mathrm{log}$ orders at 2 min treatment and gradually decreased with the extending heating time. Therefore, at $53{ }^{\circ} \mathrm{C}$ and $55{ }^{\circ} \mathrm{C}$, the enhanced heat inactivation level by LPC could be decreased even extending the heating time.

Fig. 4 shows the inactivation ratio during the shorter treatment time from 1 to $15 \mathrm{~s}$. Temperature was set to $57{ }^{\circ} \mathrm{C}$ because $S$. cerevisiae cells were effectively inactivated at $57{ }^{\circ} \mathrm{C}$ (Fig. 2). The results showed that the LPC-enhanced inactivation ratio increased from 1 to 2.5 log orders with the extending treatment time from 5 to 15 s. From these results, it can be concluded that when performing specific short heat treatment period, the LPC-enhanced inactivation level increased with the extending heating time.

\subsection{Effect of LPC on the Cytoplasmic Acidification of S. cerevisiae Cells}

We previously revealed that LPC can enhance the heat inactivating effect on bacteria to 3-5 log orders at several heating temperatures [13]. However, the increased inactivation effect enhanced by LPC was smaller in $S$. cerevisiae compared to bacteria. The accomplishment to enhance heat inactivation of LPC on bacterial cells was concluded in our previous study. We have found that the increased inactivation ratio was represented by the rise in cytoplasmic proton concentration in bacterial cell during LPC which led to the acidification of the cell. LPC can decrease the intracellular $\mathrm{pH}$ of $E$. coli to 5.5 when the inactivation ratio was enhanced from heating alone for 3 log orders [16]. This phenomenon can cause many physiological damages within the cell, resulting in the decreasing heat resistance [16, 17]. It was proposed that $S$. cerevisiae cells are less sensitive to $\mathrm{CO}_{2}$ concentration than bacterial cells because they have vacuoles which can prevent the cytoplasmic acidification of the cell by pumping out an excess proton via $\mathrm{V}^{+}$-ATPase [18]. Therefore, we evaluated cytoplasmic $\mathrm{pH}$ level of $S$. cerevisiae cells after LPC by staining the cell with Yellow/Blue DND-160, and used the fluorescent acidotropic LysoSensor probe for labeling and tracking acidic organelle. In acidic organelles Yellow/Blue DND-160 has predominantly yellow fluorescence, and in less acidic organelles it has blue fluorescence. The

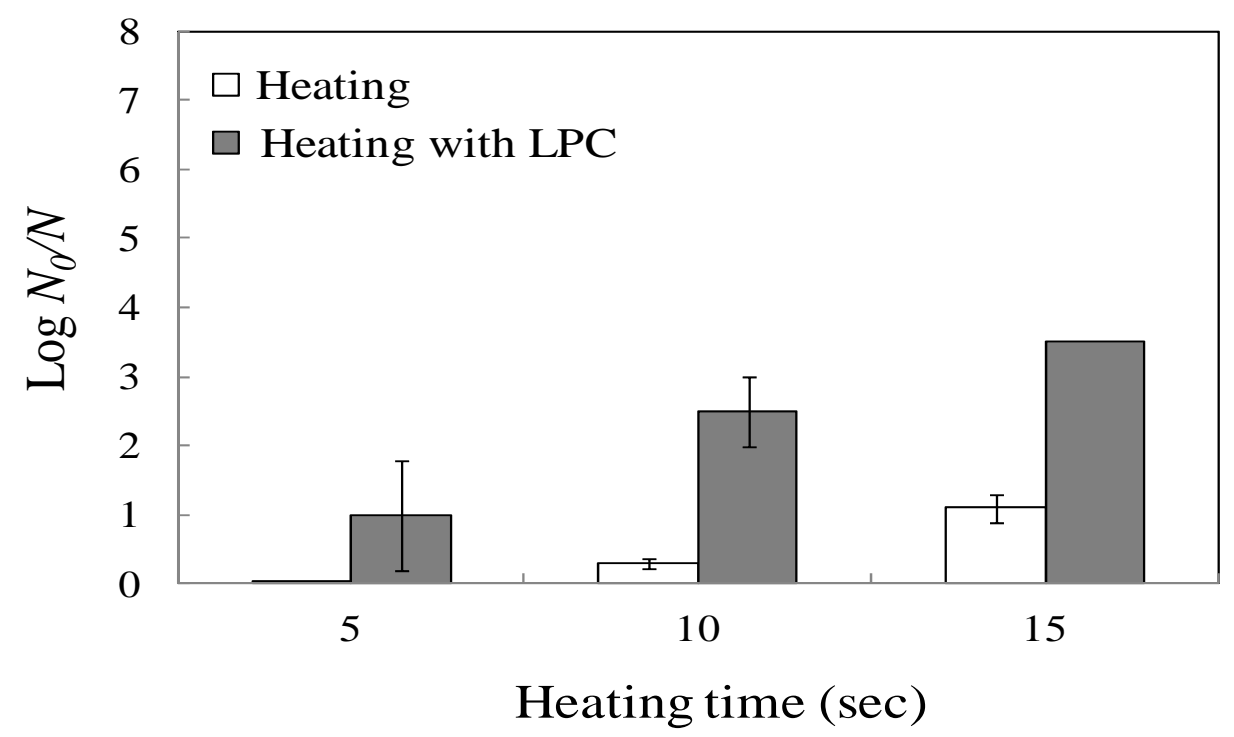

Fig. 4 Effect of heating treatment time on log inactivation ratio of $S$. cerevisiae after heating $\left(0.1 \mathrm{MPa}, 57^{\circ} \mathrm{C}, 5-15 \mathrm{~s}\right)$ and heating with LPC (1 MPa, $57^{\circ} \mathrm{C}, 5-15$ s). The initial cell concentration was $10^{8} \mathrm{CFU} / \mathrm{mL}$. 
(a)

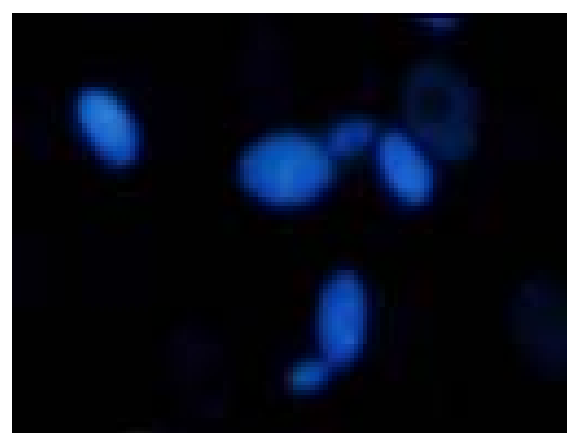

Non-treatment (b)

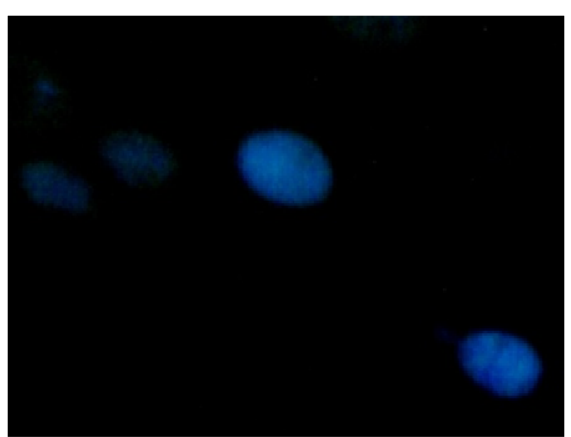

LPC

(1 MPa, $\left.4^{\circ} \mathrm{C}\right)$

Fig. 5 LysoSensor staining properties of $S$. cerevisiae cells. (a) non-treatment, (b) LPC under 1 MPa, 1 min.

results showed that similar to the untreated cell (Fig. 5a), the LPC-treated cell under $1 \mathrm{MPa}, 4{ }^{\circ} \mathrm{C}, 15 \mathrm{~min}$ showed blue fluorescence (Fig. 5b). Hence, it can be implied that LPC is macroscopically unable to acidify the cytoplasm of $S$. cerevisiae cell, resulting in the inferior inactivation ratio compared with bacterial cell. However, with short time heat inactivation, the effect of LPC to enhance the inactivation of S. cerevisiae was observed. Additional research is necessary to further explain the specific effect.

\section{Conclusions}

Short time (5 to $15 \mathrm{~s}$ ) with higher temperature $\left(57^{\circ} \mathrm{C}\right)$ is the promised condition for heating with LPC that can effectively inactivate $S$. cerevisiae. The practical application of the explored LPC condition could be proposed as an alternative technique for inactivation of S. cerevisiae in various liquid foods. As the heating condition can be operated for short time, the extent of degradation of the food flavors and nutrition can be reduced.

\section{References}

[1] M.E. Parish, D.P. Higgins, Yeasts and molds isolated from spoiling citrus products and by-products, Journal of Food Protection 52 (1989) 261-263.

[2] M.E. Parish, Microbiological concerns in citrus juice processing, Food Technology 45 (1991) 128-136.

[3] C.D. Zook, M.E. Parish, R.J. Braddock, M.O. Balaban, High pressure inactivation kinetics of Saccharomyces cerevisiae ascospores in orange and apple juices, Journal of Food Science 64 (1999) 533-535.

[4] C.R. Fellers, Sodium benzoate and benzoic acid preservatives for cider and other fruit juices, Fruit Products Journal and American Vinegar Industry 9 (1929) 113-115.

[5] A.D. Warth, Resistance of yeast species to benzoic and sorbic acids and to sulfur dioxide, Journal of Food Protection 48 (1985) 564-569.

[6] P. Loaharanu, International trade in irradiated foods: Regional status and outlook, Food Technology 43 (1989) 77-80.

[7] B.L. Qin, F.J. Chang, G.V. Barbosa-Canovas, B.G. Swanson, Nonthermal inactivation of Saccharomyces cerevisiae in apple juice using pulsed electric fields, Lebensmittel Wissenschaft and Technologie 28 (1995) 564-568.

[8] H. Ogawa, K. Fukuhisa, Y. Kubo, H. Fukumoto, Pressure inactivation of yeasts, molds, and pectinesterase in satsuma mandarin juice: Effects of juice concentration, $\mathrm{pH}$, and organic acids, and comparison with heat sanitation, Agricultural and Biological Chemistry 54 (1990) 1219-1225.

[9] F. Moerman, High hydrostatic pressure inactivation of vegetative microorganisms, aerobic and anaerobic spores in pork Marengo, a low acidic particulate food product, Meat Science 69 (2005) 225-232.

[10] H.M. Lin, Z. Yang, L.F. Chen, Inactivation of Saccharomyces cerevisiae by supercritical and subcritical carbon dioxide, Biotechnology Progress 8 (1992) 458-461.

[11] J.A. Daniels, R. Krishnamurthi, S.S.H. Rizvi, A review of effects of carbon dioxide on microbial growth and food quality, Journal of Food Protection 48 (1985) 532-537.

[12] G.J. Haas, H.E. Jr. Prescott, E. Dudley, R. Dik, C. Hintlian, L. Keane, Inactivation of microorganisms by carbon dioxide under pressure, Journal of Food Safety 9 (1989) 253-265.

[13] S. Noma, W. Klangpetch, S. Nakamura, T. Ishibashi, H. 


\section{Acidification of Saccharomyces cerevisiae}

Huang, N. Igura, et al., Effect of low-pressure carbonation on heat inactivation of yeast and bacterial vegetative cells, Food Science and Technology Research 16 (2010) 389-394.

[14] M. Shimoda, H. Kago, N. Kojima, M. Miyake, Y. Osajima, I. Hayakawa, Accelerated death kinetics of Aspergillus niger spores under high-pressure carbonation, Applied and Environmental Microbiology 68 (2002) 4162-4167.

[15] P. Gervais, I. Martínez de Marañon, Effect of the kinetics of temperature variation on Saccharomyces cerevisiae viability and permeability, Biochimica et Biophysica Acta 1235 (1995) 52-56.

[16] W. Klangpetch, S. Noma, N. Igura, M. Shimoda, The effect of low-pressure carbonation on the heat inactivation of Escherichia coli, Bioscience, Biotechnology, and Biochemistry 75 (2011) 1945-1950.

[17] S.I. Hong, Y.R. Pyun, Membrane damage and enzyme inactivation of Lactobacillus plantarum by high pressure $\mathrm{CO}_{2}$ treatment, International Journal of Food Microbiology 63 (2001) 19-28.

[18] T. Watanabe, S. Furukawa, K. Kitamoto, A. Takatsuki, R. Hirata, H. Ogihara, et al., Vacuolar $\mathrm{H}^{+}$-ATPase and plasma membrane $\mathrm{H}^{+}$-ATPase contribute to the tolerance against high-pressure carbon dioxide treatment in Saccharomyces cerevisiae, International Journal of Food Microbiology 105 (2005) 131-137. 